\title{
Halloysite Nanotubes Supported Gold Catalyst for Cyclohexene Oxidation with Molecular Oxygen
}

\author{
Zhen-Yu Cai ${ }^{1}$, Ming-Qiao Zhu ${ }^{1}$, Huan Dai ${ }^{1}$, Yi Liu ${ }^{1}$, Jian-Xin $\mathrm{Mao}^{2}$, Xin-Zhi Chen ${ }^{1}$, Chao-Hong He ${ }^{1}$ \\ ${ }^{1}$ Department of Chemical and Biochemical Engineering, Zhejiang University, Hangzhou, China \\ ${ }^{2}$ Department of Chemistry, Zhejiang University, Hangzhou, China \\ E-mail: zhumingqiao@zju.edu.cn \\ Received January 6, 2011; revised January 18, 2011; accepted January 20, 2011
}

\begin{abstract}
The selective oxidation of cyclohexene to 2-cyclohexene-1-ol and 2-cyclohexene-1-one has been investigated over Au/HNTs (HNTs: halloysite nanotubes) catalysts with molecular oxygen in a solvent-free system. The catalysts were prepared by deposition precipitation method and characterized by ICP-AES, TEM and $\mathrm{XRD}$. The results show that the catalytic performance of Au/HNTs is quite well and the catalytic activity over recycled catalyst remains highly. Moreover, the nano-size effect of gold is also reported for the reaction.
\end{abstract}

Keywords: Gold Catalyst, HNTs, Cyclohexene Oxidation, Oxygen

\section{Introduction}

The catalytic oxidation of hydrocarbons into value-added oxygenated derivatives is still a challenge in modern chemistry and industry world [1-3]. In particular, the oxidation of cyclohexene is often inefficient as there is a $\mathrm{C}=\mathrm{C}$ bound and four $\alpha-\mathrm{H}$ atoms in the cyclohexene molecule. Oxidation of cyclohexene is an important method for the synthesis of chemical intermediates like 2-cyclohexene-1-ol and 2-cyclohexene-1-one in the manufacture of high-value pharmaceuticals [4]. A greater demand for these oxidation products and increased enviromental concerns warrant the introduction of catalytic systems using heterogeneous catalyst and the environmentally friendly oxidants such as molecular oxygen or hydrogen peroxide [5]. The use of $\mathrm{H}_{2} \mathrm{O}_{2}$ is atom efficient and the only by-product is water, but the relatively high cost of $\mathrm{H}_{2} \mathrm{O}_{2}$ severely hinders its wide application in catalytic oxidation [6]. On the other hand, catalytic systems using oxygen as the oxidant instead resulted in three important advantages: the facility to separate the catalyst after the reaction, lower energy costs and a higher stability of the irreversible reaction of overoxidantion products $[7,8]$. Therefore, oxidation of cyclohexene with oxygen under solvent-free condition would be valuable.

In recent years, an increasing interest has been directed to the catalytic potential of gold catalysts [9-12]. Supported gold catalysts have been extensively studied for a wide range of oxidation reactions including $\mathrm{CO}$ oxidation [13], propylene epoxidation [14], the direct synthesis of hydrogen peroxide from oxygen and hydrogen $[15,16]$, oxidation of cyclohexane to KA oil [17-19], etc.. Particularly, the partial liquid-phase cyclohexene oxidation using gold catalysts including $\mathrm{Au} / \mathrm{C}$ and $\mathrm{Au} / \mathrm{CNTs}$ makes gold even more attractive $[20,21]$. Unfortunately, as for the $\mathrm{Au} / \mathrm{C}$ catalyst, it has good catalytic performance only with the addition of special organic solvent [20]. The performance of $\mathrm{Au} / \mathrm{CNTs}$ catalyst is influenced by the amount of TBHP [21]. Compared $\mathrm{Au} / \mathrm{C}$ and $\mathrm{Au} / \mathrm{CNTs}$, we can see that the structure of the carrier has great effect on the catalytic performance of supported gold. As silica and $\mathrm{Al}_{2} \mathrm{O}_{3}$ are quite common industrial materials as catalysts support material because of their relative stability, high surface area and low price. $\mathrm{Au} / \mathrm{Al}_{2} \mathrm{O}_{3}$ and $\mathrm{Au} / \mathrm{SiO}_{2}$ are quite effective in cyclohexane oxidation [8,22], but there is little report about aluminosilicate-supported $\mathrm{Au}$ catalyst. HNTs (halloysite nanotubes) is a special kind of aluminosilicate. The objective of this work is to report catalyst Au/HNTs of very low metal loadings and the effect of nano-size of gold on catalytic performance for the selective oxidation of cyclohexene using molecular oxygen in a solvent-free system.

\section{Experimental}

$\mathrm{Au} / \mathrm{HNTs}$ catalysts with varied gold loadings were pre- 
pared by the deposition-precipitation procedure. $2.0 \mathrm{~g}$ HNTs support was stirred in $0.5 \mathrm{mmol} \cdot \mathrm{L}^{-1} \mathrm{HAuCl}_{4}$ aqueous solution for $1 \mathrm{~h}$ at $60^{\circ} \mathrm{C}$. The $\mathrm{pH}$ of the slurry was kept at 10 adjusted with $4.0 \mathrm{~mol} \cdot \mathrm{L}^{-1}$ ammonia solution. After filtration, the resulting solid was washed twice using $20 \mathrm{~mL}$ of deionized water for each wash to remove $\mathrm{Cl}^{-}$ion. Finally, the resulting solid was dried at $80^{\circ} \mathrm{C}$ overnight and calcined at $300^{\circ} \mathrm{C}$ for $3 \mathrm{~h}, \mathrm{Au} / \mathrm{HNTs}$ was obtained.

The chemical compositions of the samples were determined by ICP-AES (IRIS Intrepid II XPS). $0.1 \mathrm{~g}$ of the solid samples was leached by $4 \mathrm{~mL}$ of aqua regia for $4 \mathrm{~h}$ and the leaching liquid was collected for determining gold. The specific surface areas were obtained by the Brunauer-Emmett-Teller (BET) method using an Autosorb-1-C instrument. A D/max-RA instrument with $\mathrm{Cu} K \alpha$ radiation with a beam voltage of $40 \mathrm{kV}$ and a beam current of $40 \mathrm{~mA}$ was used to collect the X-ray data. Transmission electron microscopy (TEM) images were obtained on a JEM-1230 at $80 \mathrm{kV}$. The samples were dispersed in ethanol and then dropped on copper-coated grid. The gold particle size distribution was obtained by measuring the diameter of metal particles.

The catalytic experiments for cyclohexene oxidation were carried out in a PTFE-lined autoclave (Capacity = $30 \mathrm{~mL}$, pressure maximum $6 \mathrm{MPa}$ ). In a typical oxidation reaction, $20 \mathrm{ml}$ cyclohexene and $0.20 \mathrm{~g}$ catalyst were placed into the autoclave. The reactor was then heated to the desired reaction temperature in oil bath under constant stirring with a magnetic stirrer. After the reaction was over, the reactor was cooled to room temperature and the liquid phase was separated from the reaction slurry. The solid catalyst was washed by acetone and dried at $80^{\circ} \mathrm{C}$ for $3 \mathrm{~h}$. Reactants and products were identified by gas chromatography-mass spectroscopy (GC-MS) as well as by comparing retention time to respective standards in GC traces. GC analyses were done using a GC 1690 instrument with a flame ionization detector (FID). The column used was an SE-54 capillary column $(30 \mathrm{~m} \times 0.32 \mathrm{~mm} \times 0.5 \mu \mathrm{m})$. N-Heptane was used as an internal standard for product analysis.

\section{Results and Discussion}

\subsection{Catalyst Characterization}

The actual gold contents and specific surface areas of samples were shown in Table 1. With the increase of gold loadings, the specific surface area of Au/HNTs catalysts differs only slightly, which means loading gold has little effect on that.

Figure 1 gives the XRD patterns of the HNTs, $\mathrm{Au}(0.37 \%) / \mathrm{HNTs}, \mathrm{Au}(0.80 \%) / \mathrm{HNTs}$ and $\mathrm{Au}(1.35 \%)$

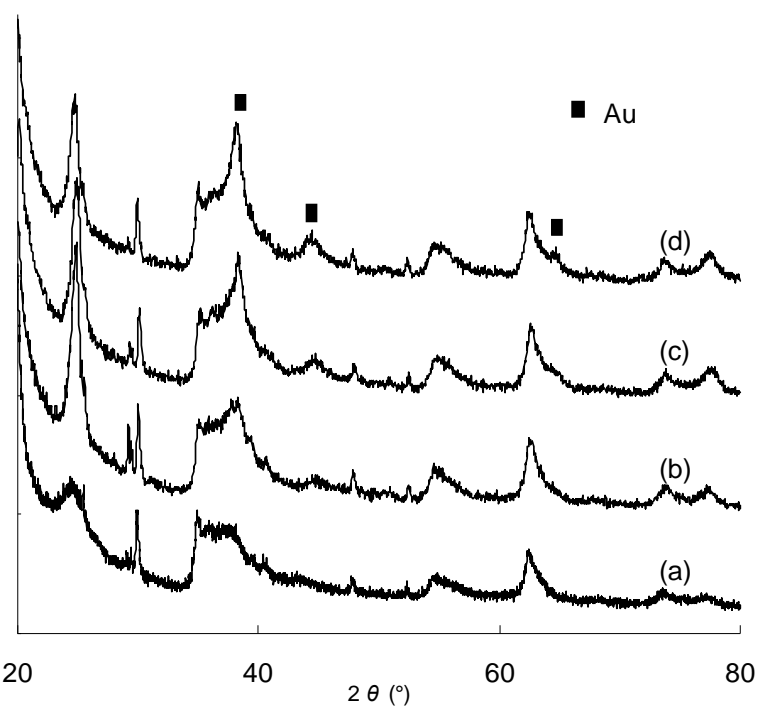

Figure 1 XRD patterns of HNTs (a), Au(0.37\%)/HNTs (b), Au(0.80\%)/HNTs (c), Au(1.35\%)/HNTs (d).

Table 1. Au content, specific surface area of HNTs and supported gold catalysts.

\begin{tabular}{|c|c|c|c|}
\hline \multirow{2}{*}{ Samples } & \multicolumn{2}{|c|}{ Au content (wt. \%) } & \multirow{2}{*}{$\begin{array}{c}\mathrm{S}_{\mathrm{BET}} \\
\left(\mathrm{m}^{2} \cdot \mathrm{g}^{-1}\right)\end{array}$} \\
\hline & Theoretical & Actual & \\
\hline HNTs & - & - & 60 \\
\hline $\mathrm{Au} / \mathrm{HNTs}$ & 0.5 & 0.37 & 57 \\
\hline $\mathrm{Au} / \mathrm{HNTs}$ & 1.0 & 0.80 & 58 \\
\hline $\mathrm{Au} / \mathrm{HNTs}$ & 1.5 & 1.35 & 58 \\
\hline
\end{tabular}

/HNTs, respectively. The typical signals of gold at $38.19^{\circ}$, $44.42^{\circ}$ and $64.57^{\circ}$ were observed and became more obvious in steps from Figure 1 (b-d), which indicated that the particle size of gold increased according to the increasing of gold content of the catalyst.

Figure 2 shows the typical TEM images of supported $\mathrm{Au} / \mathrm{HNTs}$ catalysts and the black round dots in the images are gold particles. Although gold is unevenly distributed and the particle size is discrepancy in the same sample, it is easy to see that as the gold loading changes from $0.37 \%$ to $1.35 \%$, the gold particles become bigger, agreeing well with the results of Figure 1, which means the gold loading greatly affects the particle size.

\subsection{Catalytic Oxidation of Cyclohexene}

In preliminary experiments, an uncatalyzed oxidation reaction was carried out under the typical reaction conditions as shown in Table 2 (Entry 1). There were four main products could be obtained: cyclohexene oxide, 2-cyclohexene-1-ol, 2-cyclohexene-1-one and cyclohexane-1, 2-diol, and their selectivity was $8.1 \%, 15.4 \%$, $21.7 \%$ and $23.1 \%$ respectively. Moreover, the activity of pure HNTs support was also studied under the same conditions (Table 2, Entry 2). Compared with uncata- 

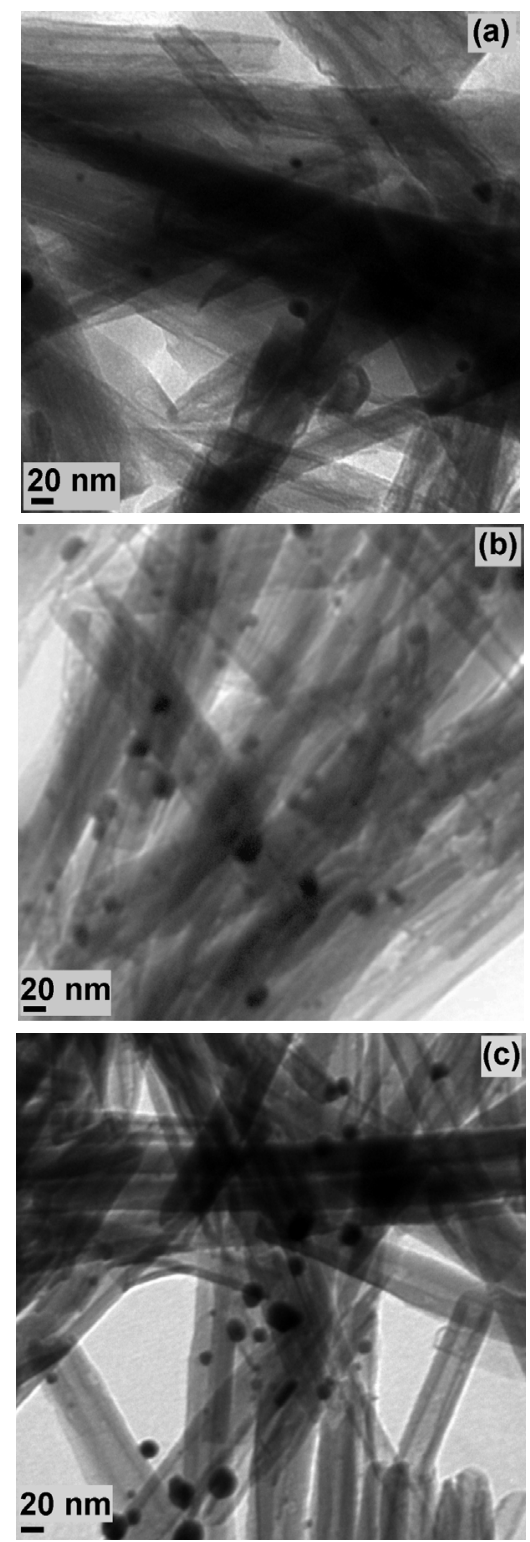

Figure 2. TEM images of Au/HNTs catalysts of (a) $0.37 \%$, (b) $0.80 \%$, (c) $1.35 \%$ Au.

Table 2. Effect of Au loadings on catalytic performance in cyclohexene oxidation $^{a}$.

\begin{tabular}{cccccc}
\hline \multirow{2}{*}{$\begin{array}{c}\text { Catalyst } \\
\text { (wt.\% Au) }\end{array}$} & $\begin{array}{c}\text { Conver- } \\
\text { sion (\%) }\end{array}$ & \multicolumn{4}{c}{ Selectivity (\%) } \\
\hline & Cy-oxide & Cy-ol & Cy-one & Cy-ol + Cy-one \\
\hline No $^{\mathrm{b}}$ & 12.1 & 8.1 & 15.4 & 21.7 & 37.1 \\
$\mathrm{HNTs}$ & 16.9 & 6.5 & 29.8 & 43.4 & 73.2 \\
$\mathrm{Au} / \mathrm{HNTs}$ & 25.9 & 4.0 & 32.5 & 46.9 & 79.3 \\
$\begin{array}{c}(0.37 \% \mathrm{Au}) \\
\mathrm{Au} / \mathrm{HNTs}\end{array}$ & 29.5 & 3.5 & 35.5 & 49.0 & 84.5 \\
$(0.80 \% \mathrm{Au})$ & & & & & 82.3 \\
$\begin{array}{c}\mathrm{Au} / \mathrm{HNTs} \\
(1.35 \% \mathrm{Au})\end{array}$ & 21.2 & 4.1 & 34.3 & 48.0 & 8
\end{tabular}

${ }^{a}$ All reactions were done with $0.20 \mathrm{~g}$ of catalyst, $20 \mathrm{~mL}$ cyclohexene, at $80^{\circ} \mathrm{C}, 12 \mathrm{~h}$, and the pressure of oxygen is $0.4 \mathrm{MPa}{ }^{b}$ The selectivity of cyclohexane-1,2-diol is $23.1 \%$. lyzed reaction, conversion of cyclohexene increased $4.8 \%$ over HNTs while the distribution of product changed a lot. No cyclohexane-1,2-diol was detected in the product as the selectivity of 2-cyclohexene-1-ol and 2-cyclohexene-1-one increased to $29.8 \%$ and $43.4 \%$ respectively.

The catalytic performance of $\mathrm{Au} / \mathrm{HNT}$ catalysts with different gold loadings was investigated for cyclohexene oxidation using molecular oxygen as an oxidant in a solvent-free system (Table 2). In this work, the best catalytic performance is $\mathrm{Au}(0.80 \%) / \mathrm{HNTs}$, which presents a conversion of $29.5 \%$, a little better than $\mathrm{Au}(0.37 \%) /$ HNTs. As gold content increased from $0.80 \%$ to $1.35 \%$, a sharp decrease of cyclohexene conversion is evident. This phenomenon may result from the different quantities of active sites of the catalysts. There existed an apparent nano-size effect of gold in cyclohexene oxidation. From the TEM images, we can see that the gold particles grow bigger as the gold content increasing. The particle sizes of $\mathrm{Au}(0.37 \%) / \mathrm{HNTs}$ are $<10 \mathrm{~nm}, \mathrm{Au}(0.80 \%) /$ HNTs are $<20 \mathrm{~nm}, \mathrm{Au}(1.35 \%) / \mathrm{HNTs}$ are $20 \sim 40 \mathrm{~nm}$. There are much more gold particles smaller than $10 \mathrm{~nm}$ of $\mathrm{Au}(0.80 \%) / \mathrm{HNTs}$ comparing with $\mathrm{Au}(0.37 \%) / \mathrm{HNTs}$ and $\mathrm{Au}(1.35 \%) / \mathrm{HNTs}$, and the $\mathrm{Au}(0.80 \%) / \mathrm{HNTs}$ has better catalytic performance. Therefore, we infer that the gold particles $<10 \mathrm{~nm}$ could be more active.

As $\mathrm{Au} / \mathrm{HNTs}(0.80 \% \mathrm{Au})$ shows the best results with respect to the conversion and the selectivity to the two desired oxygenates, it is employed to investigate the progress of the reaction with time under the typical conditions. As shown in Figure 3, the oxidation of cyclohexene make a large progress from $6 \mathrm{~h}$ to $12 \mathrm{~h}$, affording a conversion of $29.5 \%$ and $84.5 \%$ selectivity to the two desired oxygenates at $12 \mathrm{~h}$. It is also evident that the oxidation reaction gradually slowdowns with time, suggesting a gradual loss of catalytic activity of the catalyst. We believe this could be ascribed to a strong affinity of HNTs with the products formed increasing in the reaction, through which the adsorption of apolar cyclohexene on the catalyst can be suppressed.

Recycling tests were performed using $\mathrm{Au} / \mathrm{HNTs}$ $(0.80 \% \mathrm{Au})$ under the typical reaction conditions for $12 \mathrm{~h}$, and the results are given in Figure 4. Both the conversion and the overall selectivity to two oxygenates are well retained with a slightly enhanced selectivity to 2-cyclohexene-1-one and a little decreased selectivity to 2-cyclohexene-ol, suggesting a high stability of the catalyst.

In order to explain how the oxidation was occurred, and how the major products were formed, we also speculated the oxidation mechanism. The oxidation of cyclohexene with molecular oxygen initially formed 2-cyclohexene-1-hydroperoxide [23,24]. 2-Cyclohexene- 


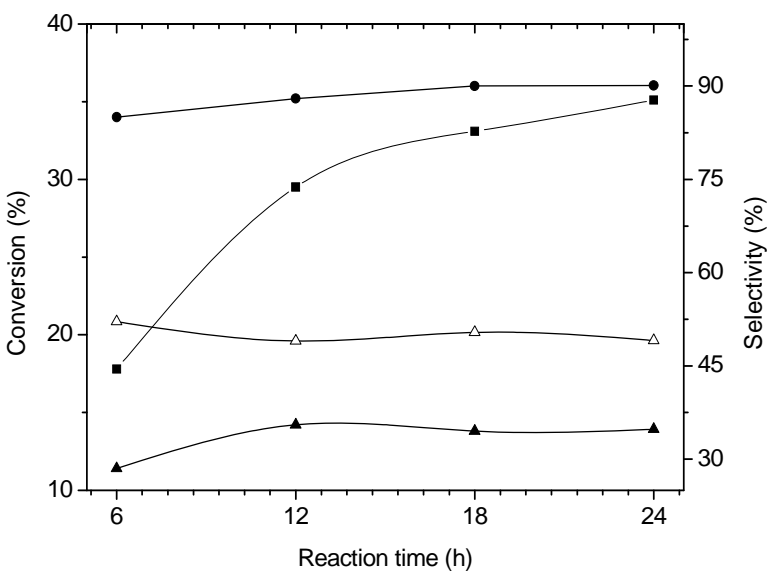

Figure 3. Cyclohexene oxidation over Au/HNTs (0.80\% Au) with different reaction time. ( $\square$ Cyclohexene, $\bullet \sum \mathrm{C}_{6}, \Delta 2$ cyclohexene-1-ol, $\triangle$ 2-cyclohexene-1-one).

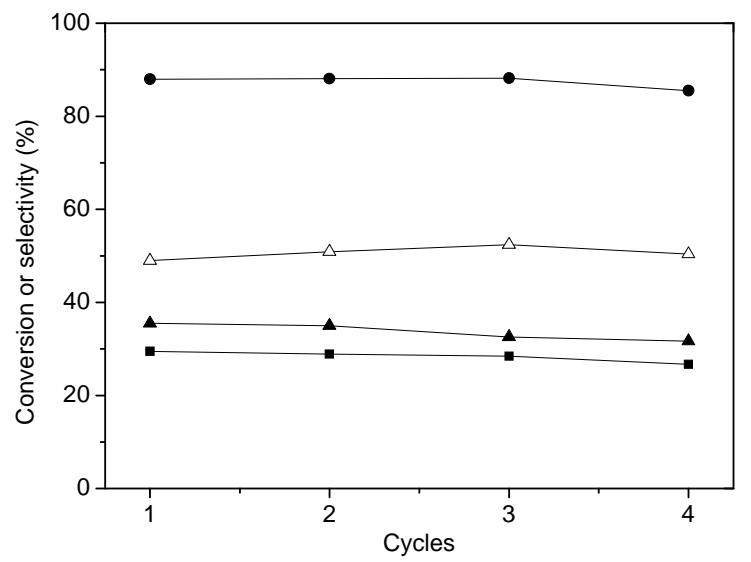

Figure 4. Results of recycling test over Au/HNTs $(0.80 \%$ Au). (घCyclohexene, $\bullet \sum C_{6}, \Delta$ 2-cyclohexene-1-ol, $\triangle 2$ cyclohexene-1-one).

1-hydroperoxide was unstable and easily formed other products as shown in Scheme 1.

\section{Conclusions}

In summary, halloysite nanotubes supported gold catalysts have been prepared successfully by the deposition-precipitation procedure. The nano-size effect of gold was found in the reaction. The results show that $\mathrm{Au} / \mathrm{HNTs}$ catalysts with the gold particles smaller than $10 \mathrm{~nm}$ are highly active for the selective cyclohexene oxidation to 2-cyclohexene-ol and 2-cyclohexene-one under relatively mild conditions.

\section{Acknowledgments}

This material is based upon work funded by financial support by Zhejiang Provincial Natural Science Founda-
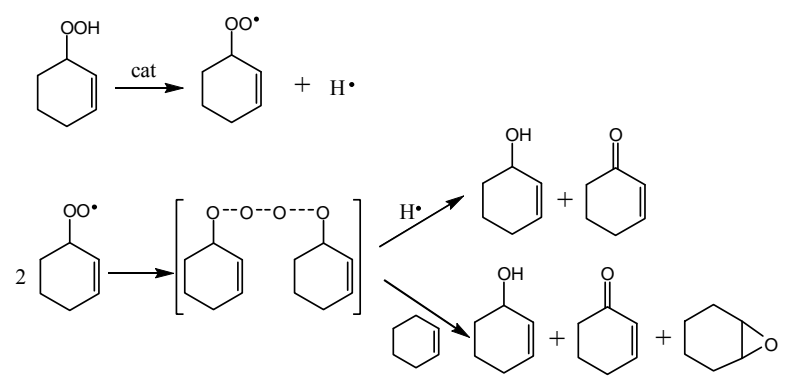

Scheme 1. Radical-chain sequence mechanism of 2-Cyclohexene1-hydroperoxide to form other products.

tion of China under Grant No. Y4080247 and No. R4090358.

\section{References}

[1] S. Mukherjee, S. Samanta, B. C. Roy and A. Bhaumik, "Efficient Allylic Oxidation of Cyclohexene Catalyzed by Immobilized Schiff Base Complex Using Peroxides as Oxidants," Applied Catalysis A, Vol. 301, No. 1, 2006, pp. 79-88.

[2] A. E. Shilov and G. B. Shul'pin, "Activation of C-H Bonds by Metal Complexes," Chemical Reviews, Vol. 97, No. 8, 1997, pp. 2879-2932. doi:10.1021/cr9411886

[3] R. Luque, S. K. Badamali, J. H. Clark, M. Fleming and D. J. Macquarrie, "Controlling Selectivity in Catalysis: Selective Greener Oxidation of Cyclohexene under Microwave Conditions," Applied Catalysis A, Vol. 341, 2008, pp. 154-159.

[4] Z. Y. Cai, M. Q. Zhu, J. Chen, Y. Y. Shen, J. Zhao, Y. Tang and X. Z. Chen, "Solvent-Free Oxidation of Cyclohexene over Catalysts Au/OMS-2 and Au/La-OMS-2 with Molecular Oxygen," Catalysis Communications, Vol. 12, No. 3, 2010, pp. 197-201. doi:10.1016/j.catcom. 2010.09.014

[5] Z. H. Weng, J. Y. Wang, S. H. Zhang, C. Yan and X. G. Jian, "Efficient Oxidation of Cyclohexene over Tetrakis (Diperoxomolybdo) Phosphate Immobilized on Poly (Phthalazinone Ether Sulfone Ketone) with Hydrogen Peroxide," Applied Catalysis A, Vol. 339, No. 2, 2008, pp. 145-150.

[6] X. J. Meng, K. F. Lin, X. Y. Yang, Z. H. Sun, D. Z Jiang and F. S. Xiao, "Catalytic Oxidation of Olefins and Alcohols by Molecular Oxygen under Air Pressure over $\mathrm{Cu}_{2}(\mathrm{OH}) \mathrm{PO}_{4}$ and $\mathrm{Cu}_{4} \mathrm{O}\left(\mathrm{PO}_{4}\right)_{2}$ Catalysts," Journal of $\mathrm{Ca}$ talysis, Vol. 218, No. 2, 2003, pp. 460-464. doi:10.1016/ S0021-9517(03)00079-4

[7] S. E. Dapurkar, H. Kawanami, K. Komura, T. Yokoyama and Y. Ikushima, "Solvent-Free Allylic Oxidation of Cycloolefins over Mesoporous CrMCM-41 Molecular Sieve Catalyst at 1 atm Dioxygen," Applied Catalysis A, Vol. 346, 2008, pp. 112-116.

[8] L. X. Xu, C. H. He, M. Q. Zhu, K. J. Wu and Y. L. Lai, "Silica-Supported Gold Catalyst Modified by Doping with Titania for Cyclohexane Oxidation," Catalysis Let- 
ters, Vol. 118, 2007, pp. 248-253. doi:10.1007/s10562007-9178-6

[9] N. R. Shiju and V. V. Guliants, "Recent Developments in Catalysis Using Nanostructured Materials," Applied Catalysis A, Vol. 356, No. 1, 2009, pp. 1-17.

[10] G. J. Hutching, "Gold Catalysis in Chemical Processing," Catalysis Today, Vol. 72, 2002, pp. 11-17. doi:10.1016 /S0920-5861(01)00473-4

[11] J. H. Clark, "Catalysis for Green Chemistry," Pure and Applied Chemistry, Vol. 73, No. 1, 2001, pp. 103-111. doi:10.1351/pac200173010103

[12] A. S. K. Hashmi, "The Catalysis Gold Rush: New Claims," Angewandte Chemie International Edition, Vol. 44, No. 43, 2005, pp. 6990-6993. doi:10.1002/anie.2005 02735

[13] M. Haruta, T. Kobayashi, H. Sano and N. Yamada, "Novel Gold Catalysts for the Oxidation of Carbon Monoxide at a Temperature Far Below $0^{\circ} \mathrm{C}$," Chemistry Letters, 1987, pp. 405-408. doi:10.1246/cl.1987.405

[14] A. K. Sinha, S. Seelan, S. Tsubota and M. Haruta, "Catalysis by Gold Nanoparticles: Epoxidation of Propene," Topics in Catalysis, Vol. 29, 2004, pp. 95-102. doi:10.1023/B:TOCA.0000029791.69935.53

[15] P. Landon, P. J. Collier, A. F. Carley, D. Chadwick, A. J. Papworth, A. Burrows, C. J. Kiely and G. J. Hutchings, "Direct Synthesis of Hydrogen Peroxide from $\mathrm{H}_{2}$ and $\mathrm{O}_{2}$ Using Pd and Au Catalysts," Physical Chemistry Chemical Physics, Vol. 5, 2003, pp. 1917-1923. doi:10.1039/ b211338b

[16] F. Menegazzo, M. Signoretto, M. Manzoli, F. Boccuzzi, G. Cruciani, F. Pinna and G. Strukul, "Influence of the Preparation Method on the Morphological and Composition Properties of $\mathrm{Pd}-\mathrm{Au} / \mathrm{ZrO}_{2}$ Catalysts and Their Effect on the Direct Synthesis of Hydrogen Peroxide from Hydrogen and Oxygen," Journal of Catalysis, Vol. 268, No. 1, 2009, pp. 122-130. doi:10.1016/j.jcat.2009.09.010

[17] L. X. Xu, C. H. He, M. Q. Zhu, K. J. Wu and Y. L. Lai, "Surface Stabilization of Gold by Sol-Gel Post-modification of Alumina Support with Silica for Cyclohexane Oxidation," Catalysis Communications, Vol. 9, No. 5, 2008, pp. 816-820. doi:10.1016/j.catcom.2007.09.005

[18] R. Zhao, D. Ji, G. Lv, G. Qian, L. Yan, X. Wang and J. Suo, "A Highly Efficient Oxidation of Cyclohexane over Au/ZSM-5 Molecular Sieve Catalyst with Oxygen as Oxidant," Chemical Communications, 2004, pp. 904-905. doi:10.1039/b315098d

[19] K. Zhu, J. C. Hu and R. Richards, "Aerobic Oxidation of Cyclohexane by Gold Nanoparticles Immobilized upon Mesoporous Silica," Catalysis Letters, Vol. 100, 2005, pp. 195-199. doi:10.1007/s10562-004-3454-5

[20] M. D. Hughes, Y. J. Xu , P. Jenkins, P. McMorn, P. Landon, D. I. Enache, A. F. Carley, G. A. Attard, G. J. Hutchings, F. King, E. H. Stitt, P. Johnston, K. Griffin and C. J. Kiely, "Tunable Gold Catalysts for Selective Hydrocarbon Oxidation under Mild Conditions," Nature, Vol. 437, 2005, pp. 1132-1135. doi:10.1038/nature04190

[21] B. D. Li, P. He, G. Q. Yi, H. Q. Lin and Y. Z. Yuan, "Performance of Gold Nanoparticles Supported on Carbon Nanotubes for Selective Oxidation of Cyclooctene with Use of $\mathrm{O}_{2}$ and TBHP," Catalysis Letters, Vol. 133, 2009, pp. 33-40. doi:10.1007/s10562-009-0171-0

[22] L. X. Xu, C. H. He, M. Q. Zhu and S. Fang, "A Highly Active $\mathrm{Au} / \mathrm{Al}_{2} \mathrm{O}_{3}$ Catalyst for Cyclohexane Oxidation Using Molecular Oxygen," Catalysis Letters, Vol. 114, 2007, pp. 202-205. doi:10.1007/s10562-007-9058-0

[23] H. Weiner, A. Trovarelli and R. G. Finke, "Expanded Product, Plus Kinetic and Mechanistic, Studies of Polyoxoanion-based Cyclohexene Oxidation Catalysis: The Detection of $\sim 70$ Products at Higher Conversion Leading to a Simple, Product-based Test for the Presence of Olefin Autoxidation," Journal of Molecular Catalysis A: Chemical, Vol. 191, No. 2, 2003, pp. 217-252. doi: 10.1016/S1381-1169(02)00344-8

[24] G. B. Shul'pin, Y. N. Kozlov, S. N. Kholuiskaya and M. I. Plieva, "Oxidations by the System 'Hydrogen Peroxide$\left[\mathrm{Mn}_{2} \mathrm{~L}_{2} \mathrm{O}_{3}\right]^{2+}(\mathrm{L}=1,4,7$-trimethyl-1,4,7-tri-azacyclononane)oxalic acid'. Part 11. Degradation of Dye Rhodamine 6G and Oxygenation of Cyclohexene," Journal of Molecular Catalysis A: Chemical, Vol. 299, No. 2, 2009, pp. 77-87. 